\title{
The Role of the Composite and Biologic Meshes in the Trocar Site Hernia Repair Following Laparoscopic Surgery
}

\author{
BOGDAN SOCEA ${ }^{1 *}$, ALEXANDRU CARAP ${ }^{1}$, OVIDIU GABRIEL BRATU2, CAMELIA CRISTINA DIACONU³, MIHAI DIMITRIU, \\ LAURA ILEANA SOCEA ${ }^{5}$, SIMONA BOBIC ${ }^{1}$, VLAD DENIS CONSTANTIN ${ }^{1}$ \\ ${ }^{1}$ Sf. Pantelimon Clinical Emergency Hospital, General Surgery, 340-342 Sos. Pantelimon, 021659, Bucharest, Romania \\ ${ }^{2}$ Central Military Hospital, Urology Clinic, 134 Calea Plevnei, 010825, Bucharest, Romania \\ ${ }^{3}$ Clinical Emergency Hospital of Bucharest, Internal Medicine Clinic, 8 Calea Floreasca, 01446,1 Bucharest, Romania \\ ${ }^{4}$ Sf. Pantelimon Clinical Emergency Hospital, Ginecology Clinic, 340-342 Sos. Pantelimon, 021659, Bucharest, Romania \\ ${ }^{5}$ Carol Davila University of Medicine and Pharmacy, Faculty of Pharmacy, Organic Chemistry Department, 6 Traian Vuia Str., \\ 020956, Bucharest, Romania
}

\begin{abstract}
The increasing proportion of laparoscopic interventions in the surgical centers has, also, determined an increased incidence of specific complications, such as trocar hernia. Nowadays, there is no unanimously agreed concensus regarding the optimal closure technique of the trocar incision, wether it should include the suture of the aponeurosis or not at the $10 \mathrm{~mm}$ ports. There is, also, no consensus regarding the proper surgical technique for the trocar hernia repair-alloplastic or tissue repair technique. The purpose of the study is to present our experience on the alloplastic repair of the trocar hernias. It is a retrospective study that analyzes the results obtained by our clinicalteam regarding the alloplastic repair of the trocar hernias, over a five-year period, between January 2011 and December 2015. The recurrence and the occurrence rates of different complications (seroma, neuroma with postoperative pain, parietal infiltration, infections and mesh rejection), depending on the type of mesh used for the surgical repair,are studied.
\end{abstract}

Keywords: trocar site hernia, biological mesh, composite mesh, collagen coated mesh

Along with the continually increasing frequency of laproscopic interventions in the surgical field, specific complications, such as trocar hernia, have appeared, with a variable incidence, complicating the evolution of the patients through the relatively high morbidity and mortality rates.

The first trocar hernia complicated by bowel obstruction, following laparoscopic cholecystectomy, was mentioned in the medical literature in 1191 [1].

An incidence value between 1 and $22 \%$ has been reported [2-4], even though the real incidence may be higher, taking into consideration the fact that most of the cases are asymptomatic or are not reported or followedup [5].

Over 100 types of alloplastic meshes are available nowadays and are being used for the surgical repair of the hernias [6].

\section{Experimental part}

Material and method

From our surgical department, 27 cases of patients suffering from trocar hernias underwentalloplastic surgical repair between J anuary 2011 and December 2015.

3 cases associated umbilical hernia that was repaired using the laparoscopic method, by placing a dual mesh prosthesis, containing a collagen sheet, inside the peritoneal cavity (polietilen-collagen Parietex). For the rest of the patients, the onlay technique was performed, using polipropilen meshes, in most cases (the synthetic mesh group, $n=19$ ), or composite or biologic meshes for 5 cases (the composite mesh group, $\mathrm{n}=5$ ). The postoperative results from the two groups were, thus, analyzed and compared.

\section{Results and disscusions}

All trocar hernia cases presented and analyzed within the aformentioned 5-year period, occured at the supraumbilical portsite, following the placement of the 10 $\mathrm{mm}$ trocar (optic trocar). Figure 1 is relevant for the clinical aspect of the one of the cases. Moreover, the medical literature reports the presence of the $5 \mathrm{~mm}$ trocar site hernia as being a very rare complication, most of them appearing at the site of the trocars with a diameter of $10 \mathrm{~mm}$ or higher [7].

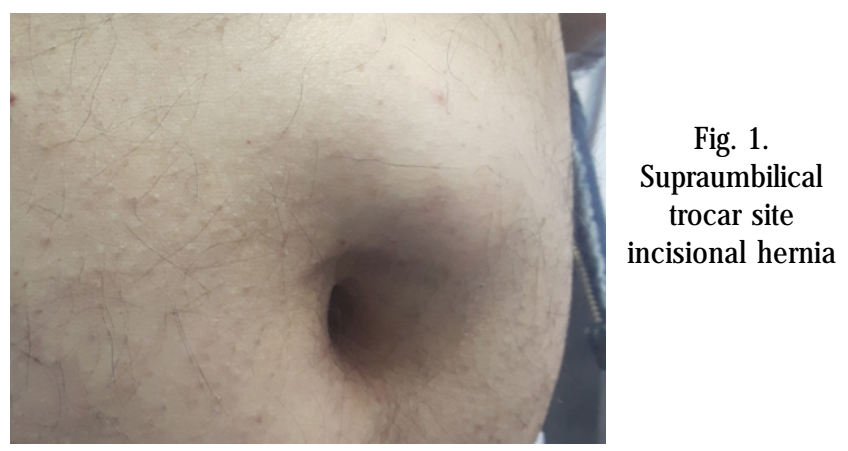

Along with the practical tradition of the surgical department, incisions for the optic trocar are made approximately $1 \mathrm{~cm}$ above the umbilicus, arcuate or linear, followed by a minimal incision $(1-1.5 \mathrm{~cm})$ on the median line of aponeurosis, superior to the umbilical ring. Then, the optic trocar is introduced by the open method. For some patients, the fascial opening of the aponeurosis may be enlarged in order to facilitate the surgical extraction of the organ. The aponeurosis suture at this level is routinely performed in all patients. For the other $10 \mathrm{~mm}$ trocar sites (other locations), and for the $5 \mathrm{~mm}$ trocars, the suture of the aponeurosis is not routinely used. 
The anamnestic data revealed that the interval between the primary laparoscopic surgery and the appearance of trocar hernia varied, ranging from 2 months to 52 months, with an average of 13.7 months. An early onset of the trocar hernia was considered to be at less than 6 months after the primary intervention ( $n=11$ patients), and a late onset after 6 months ( $n=16$ patients). The body mass index (BMI) from the two sub-groups was analyzed.

The BMI was significantly higher in the early onset subgroup compared to the late onset subgroup ( $33.67 \mathrm{vs.}$ 26.89). Thus, an increased body mass index represents an important risk factor for the development of trocar hernia and its early onset, up to 6 months after the first surgical intervention.

Seroma, hematoma or postoperative infection at the supraombilical trocarsite were present in the 17 of the 27 patients (62.96\%), these complications being, also, considered risk factors for later development of incisional hernias at the trocar site.

Analyzing the demographic data of the two groups of patients (synthetic versus composite mesh group), it has been found a homogeneous distribution of the incisional hernia at the supraombilical trocar site, when age and gender groups were taken into consideration (fig. 2, 3).

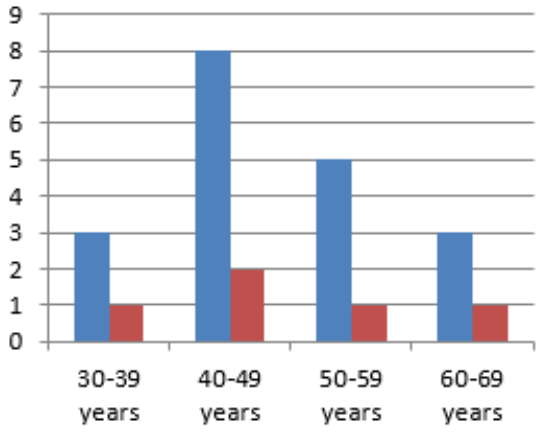

- Synthetic meshes $(47,3$ years)

Composite meshes(45.2 years)

Fig. 2

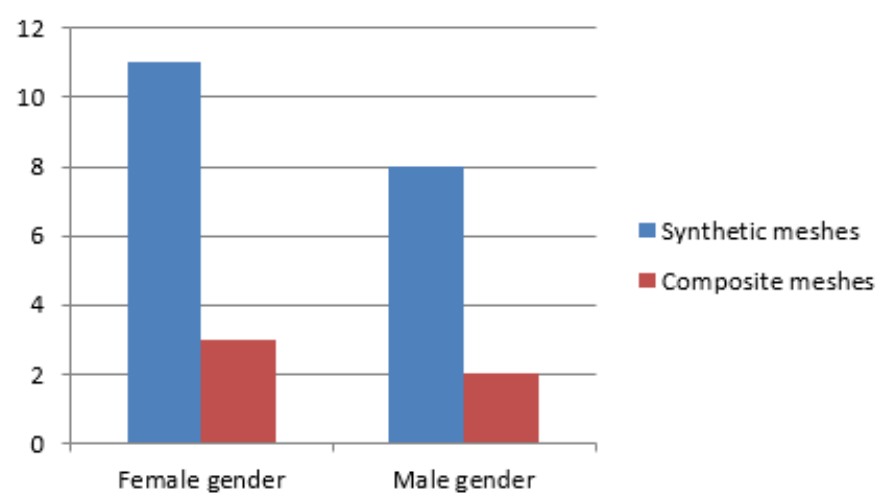

Fig. 3

The global incidence of the incisional hernia at the trocar site is approximately $1 \%$, in comparison with the 3-20\% incidence following open surgery [8]. Several risk factors have been described to have a great impact on the development of this complication, such as the design of the trocar, its diameter, preexisting parietal defect, obesity, type of lax connective tissue. In the obese patients, the risk of developing incisional hernias is increased by the higher intra-abdominal pressure and by the high adiposity of the preperitoneal and proaponeurotic layers. The routine suture of the aponeurosis at the sites of the $10 \mathrm{~mm}$ trocars represents a widespread practice, in order to avoid the incisional hernias, insufficient data regarding the proper surgical attitude towards the $5 \mathrm{~mm}$ trocars being available with most of the data supporting the conservative management, without suture.

The often difficultaccess due to small skin incision, thick subcutaneous fat, lack of good visibility, and the fear of suturing and injuring the bowel, can increase the risk of complications through an incorrect identification of structures and a defect in the technique (incorrect suture of the aponeurosis).

In our study, all trocar site incisional hernias appeared at the site of the $10 \mathrm{~mm}$ trocars. There is no data in the medical literature regarding the link between the incidence and the localization of the hernia. The only type of hernia encountered in our study is represented by the supraombilical incisional hernia, the lack of muscular abdominal layer atthis level and the high frequency of local wound infections or seroma due to the extraction of the gallbladder through this port, being considered one of the main reason for its high incidence.

Taking into consideration the fact that the diameter of the trocar may represent an important risk factor for the occurence of the incisional hernia, the use of small diameter trocar is gradually becomming a new techincal standard.

There is no consensus regarding the optimal treatment strategy in the medical literature. The published results are based on small studies.

There are studies that show similar results between the simple suture of the defect and the alloplastic method, in the case of small hernias with a diameter of under $2-3 \mathrm{~cm}$ [7]. The alloplastic technique was used in all cases of the present study, considering the fact that the previous simple suture of the aponeurosis proved to be inefficient, the alloplastic method being associaed with a low rate of reccurence.

For 3 patients the hernia repair was made under laparoscopy, using the sublay method, for the rest of the patients (24) the repair being made using open surgery, through an iterative skin incision, marking (fig. 4) and suturing (fig. 5) of the aponeurotic defect, followed by the onlay attachement of the mesh. The advantages of the technique are represented by the short operating or anesthetic time (median time - 43 min, epidural or spinal anesthesia). The median operating time in the cases that underwent open surgery was not influenced by the type of the mesh used and it was significantly shorter in comparison with the median time needed for the laparoscopic interventions (86 min).

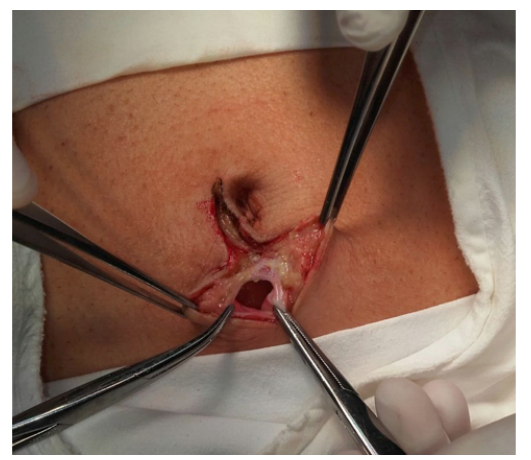

Fig. 4. Macroscopic aspect of the sutured aponeurosis, before attaching the mesh using the onlay technique

Postoperative drainage of the proaponeurotic space was not used in any of the patients inlcuded in the study, taking into consideration the relative low grade of dissection or tissue decolation during the surgical intervention. A suture of the subcutaneous adipose tissue was made for 19 patients out of the 24 that underwent open surgery.

The median postoperative hospital stay was 2.26 days, with no significat differences between the patients possibly determined by the type of mesh used. 


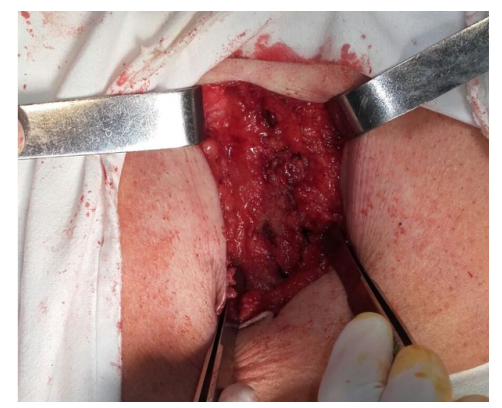

Fig. 5. Intraopeartive view highlighting the aponeurotic defect- incisional hernia at the trocar site

During the follow up interval, there was a single case of hernia reccurence after onlayalloplastic procedure using polypropylene mesh ( $4 \%$ incidence in the 24 patients group), the typ of mesh not being relevant for the risk of reccurence. The median follow up interval was 17 months for 20 patients, the length of the interval being limited mainly by the low number of compliant patients.

The other types of complications, such as seroma, postoperative infetion, neuroma or mesh rejection, were analyzed. There were no such complications for the 3 patients that underwent laparoscopic surgery or for the 5 cases for which composite meshed were used for the repair of the aponeurotic deffect. 2 out of 3 patient treated by means of laparoscopic surgery had chronic postoperative pain. There were 3 cases of postoperative seroma in the group that used polypropylene mesh for the repair of the hernia, with no such complication in the group that used composite mesh.

Taking into consideration tha fact that, usually, the complications are minimal, can autolimit or be easily repaired, and the high cost of composite or biologic meshes, itcan be concluded that the onlay technique using polypropilene meshes for the repair of the trocar hernias represents the optimal solution for the patients.

The composite and biologic meshes, when available, are associated with a high tolerability. The laparoscopic sublay technique using dual mesh is indicated for the cases that have concomitant trocar hernia and umbilical hernia, allowing the simultanous repair of the both.

It is well known the fact that the use of meshes in a contamined surgical field is forbidden. All the patients included in the study did not have complicated hernias, thus allowing the use of the prosthetic materials for the reinforcement of the abdominal wall.

The justification of the high cost of composite or biological mesh is particularly related to its need in the contaminated surgical environment, when the use of polypropylene mesh is forbidden [9-11].

It will also be of interest to study the use of prostheses impregnated with new antimicrobial substances in potentially contaminated surgical fields (intestinal obstruction with bacterial translocation) [12].

Advanced age is also a risk factor [13]. In our study, how ever, the mean age was under 50 years of age.

Usually the diagnosis of trocar site complications is based on the clinical data. Some cases remain asymptomatic until the diagnosis is established by the computer tomography. Mostcases remain uncomplicated, but complications such as bowel strangulation (Richter type) are possible [14].

The disadvantages of the present study are related to the relatively small number of patients included and its retrospective character.

\section{Conclusions}

Given that the laparoscopy will gain more popularity in modern surgery and that there is no relevant information on the trocar site complications, the aim of the study is to contribute to the prevention and the development of optimal repair technique of the complications.

The aponeurosis suture for trocar holes with a diameter of $10 \mathrm{~mm}$ or more is recommended, especially in obese patients.

Obesity (BMI over 30 ) predisposes to the early appearance (under 6 months) of trocar hernia.

The risk of hernia for $5 \mathrm{~mm}$ trocars is negligible, with no need for aponeurosis suture. We did not record 10-mm trocar hernias placed in the flank or the epigastric region, making the aponeurosis suture in these locations seem useless.

The laparoscopic technique requires dual-mesh, general anesthesia, being suitable for multiple concomitant lesions and can be accompanied by a more intense postoperative pain.

The onlayalloplastic repair of trocar hernias remains a good option with significantly reduced operating time and shorter exposure to epidural anesthesia. The availability of composite / biologic meshescan prevent complications, being better tolerated and with reduced associated septic risk, in their absence, the polypropylene mesh remaining a fair option.

\section{References}

1. MAIO A., RUCHMAN RB. J. Comput. Assist. Tomogr., 15, 1991, p. 1054-5

2. HUSSAIN A., MAHMOOD H., SINGHAL T., BALAKRISHNAN S., NICHOLLS J., EL-HASANI S. J.S.L.S., 13, 2009, p. 346-9

3. DI L.N., COSCARELLA G., LIROSI F., GASPARI A. J.S.L.S., 6, 2002, p. 181-3

4. DI L.N., COSCARELLA G., LIROSI F., PIETRANTUONO M., SUSANNA

F., GASPARI A. Chir. Ital., 57, 2005, p. 87-90

5. JAYARAMAN S., RAO S.D. Indian J. Surg., 75, 2013, p. 488-91 6. CONSTANTIN V.D., CARP A., SOCEA B., FICAI A., ALBU M.G., PAUNICAPANEA G. Romanian J ournal of Materials, 45, nr. 3, 2015, p. 290-7

7. LAMBERTZ A., STUBEN B.O., BOCK B., EICKHOFF R., KROH A., KLINK C.D., NEUMANN U.P., KRONES C.J. Ann. Med. Surg. (Lond.), 14, nr. 2 (feb), 2017, p. 8-11

8. HOLZINGER F., KLAIBER C. Chirurg., 73, 2002, p. 899-904

9. KIM M., OOMMEN B., ROSS S.W., LINCOURT A.E., MATTHEWS B.D., HENIFORD B.T., AUGENSTEIN V.A. Surg. Technol. Int., 25, nr. 11 (nov), 2014, p. 114-21

10. MADANI A., NICULISEANU P., MARINI W., KANEVA P.A., MAPPINKASIRER B., VASSILIOU M.C., KHWAJA K., FATA P., FRIED G.M., FELDMAN L.S. Surg. Endosc., 31 nr. 2 (feb), 2017, p. 861-71, doi: 10.1007/s00464-016-5044-1. Epub 2016] un 22.

11. SOCEA B., SOCEA L.I., BRATU O.G., MASTALIER B., DIMITRIU M., CARAP A., CONSTANTIN V.D, Mat. Plast,, 55, no. 1, 2018, p. 79

12. SOCEA L.I., SARAMET G., DRAGHICI C., SOCEA B., CONSTANTIN V.D., RADU POPESCU M.A. J. Serb. Chem. Soc., 80, nr. 12, 2015, p. $1461-70$

13. DINCEL O., BASAK F., GOKSU M. North. Clin. Istanb., 2, nr. 3, 2015, p. 210-4

14. ROSSI A., MCLAUGHLIN D., WITTE S., LYNSUE J., HALUCK R.S., ROGERS A.M. J. Laparoendosc. Adv. Surg. Tech., nov. 2016, doi: 10.1089/lap.2016.0483. [Epub ahead of print]

Manuscvript received: 21.01 .2018 